\title{
MECHANICAL FUNCTIONALISATION OF Cutting InSerts B Y Machine Hammer Peening
}

\author{
Manuel Reiter*, Stephan Krall \& Friedrich Bleicher
}
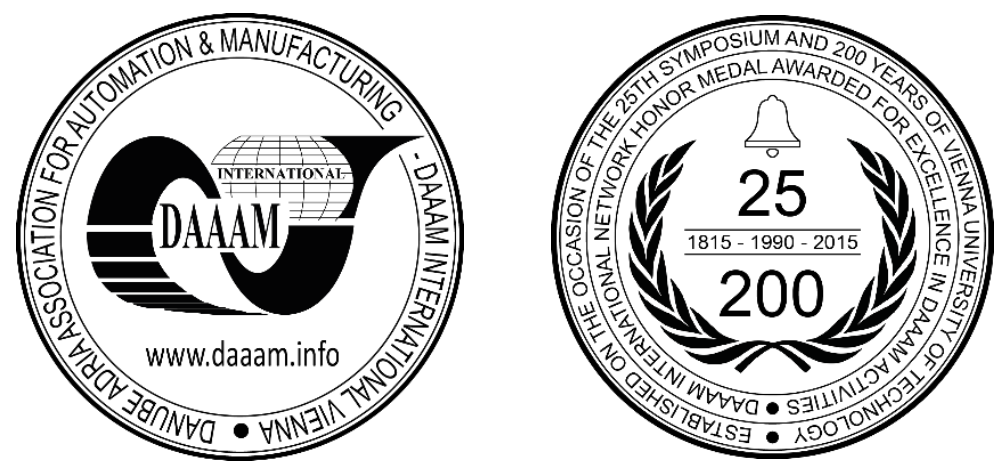

This Publication has to be referred as: Reiter, M[anuel]; Krall, S[tephan] \& Bleicher, F[riedrich] (2017). Mechanical Functionalisation of Cutting Inserts by Machine Hammer Peening, Proceedings of the 28th DAAAM International Symposium, pp.0767-0772, B. Katalinic (Ed.), Published by DAAAM International, ISBN 978-3-902734-11-2, ISSN 1726-9679, Vienna, Austria

DOI: $10.2507 / 28$ th.daaam.proceedings.108

\begin{abstract}
Modern developments of functional components result in increasing demands on new materials and their characteristics. Therefore, the complexity of machining applications is also rising, and the challenges concerning wear resistance and longer lifetime of cutting tools continue to grow. The focus of this work is on the mechanical functionalisation of cutting inserts made of cemented tungsten carbide with a Ti-Al-N coating. The functionalisation of the cutting tools is caused by machine hammer peening of the cutting insert's rake face in order to influence surface-near layers, which results in material compaction of the treated areas and an inducement of residual compressive stresses.
\end{abstract}

Keywords: machine hammer peening; cutting insert; cemented carbide; Ti-Al-N coating; residual stress

\section{Introduction}

Over the last years, the process of machine hammer peening (MHP) has grown to an important method for influencing the surface properties and the mechanical state of the subsurface material layers (see e.g. [1]). By the use of MHP, the treated surfaces may show increased surface hardness and residual compressive stresses in near-surface layers [2]. These characteristics may be advantageous when it comes to cutting tools that are exposed to extremely abrasive wear. In the present work, cutting inserts (insert code: TCMW 16T308; cemented tungsten carbide base body with Ti-Al-N coating) that are usually applied for the simultaneous machining of a material combination (a casted aluminium-alloy with a wire-arc sprayed coating; for further relevant information regarding material combinations and machining types, see [3]) get mechanically functionalised.

During this simultaneous machining process, the cutting insert's rake face is exposed to significant normal stress gradients between the cutting areas of the malleable aluminium and the abrasive, wear-resistant spray-coating. For this reason, the rake faces of the mentioned cutting inserts are treated by means of the machine hammer peening technology to induce residual compressive stresses that should prevent tearing up of the coating (initially caused by the occurring tensile stresses in the coating due to the normal stress discrepancy on the rake face). 


\section{Machine hammer peening}

Machine hammer peening is based on the oscillating movement of an axially guided ram with a tool tip on its end (mostly spherical in shape), which periodically comes in contact with the workpiece. The actuator, by the company accurapuls, used for this research work functions using an electromagnetic principle. A magnetic reaction force is generated by an alternating sinusoidal current applied on a plunger coil within a magnetic field in the MHP-system. The therefore resulting Lorentz force accelerates the ram over the stroke distance towards the surface, where the impact of the tool tip at the surface transforms its kinetic energy into elastoplastic deformation of the surface [2]. The ram may be equipped with different spherical tool tips, in order to use appropriate materials for the various applications of the machine hammer peening process. The NC-control of the machining centre, in which the actuator is mounted, provides the relative movements between tool (the oscillating MHP-actuator) and workpiece.

The composition of the actuator and the relevant process parameters are depicted in Fig. 1.

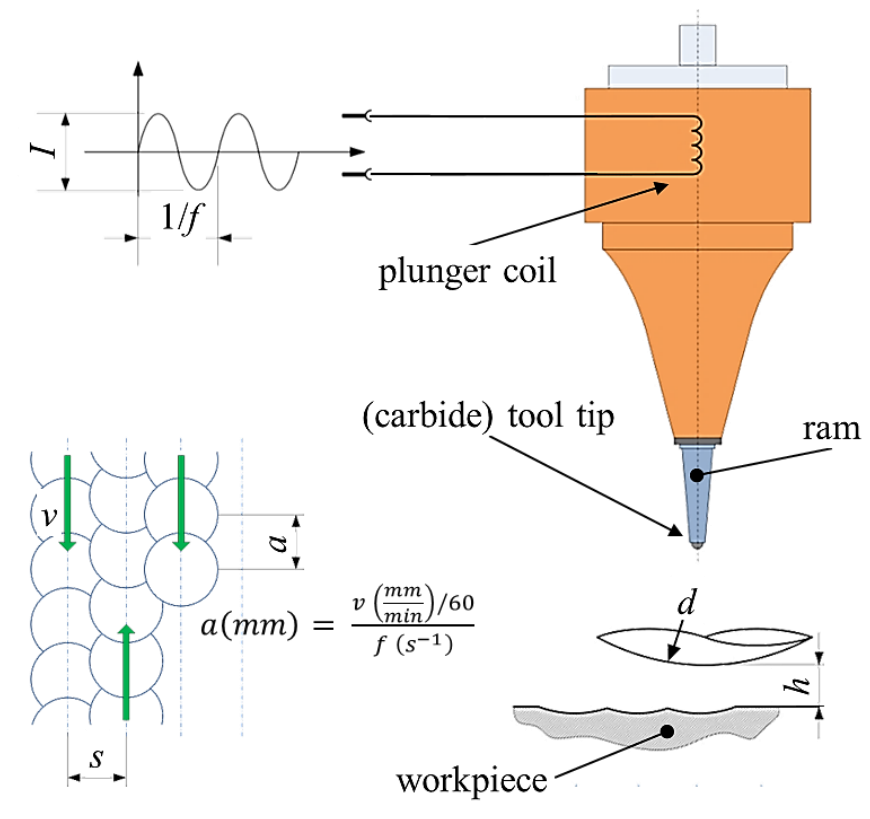

Fig. 1. Schematic overview of the electromagnetic MHP-actuator and the relevant process parameters:

$I$...intensity (percentage of voltage amplitude); $f$..frequency $(\mathrm{Hz}) ; v \ldots$ feed rate $(\mathrm{mm} / \mathrm{min})$;

$a .$. distance of indentation $(\mathrm{mm}) ; s \ldots$ stepover distance $(\mathrm{mm}) ; d \ldots$ tool tip diameter $(\mathrm{mm}) ; h \ldots$ stroke $(\mathrm{mm})(\mathrm{cf} .[1])$.

Previous works like [4],[5] have shown that due to the preceding MHP-treatment on metallic materials, significant residual compressive stresses have been detected in the near-surface layers of the covered areas. These are higher in orthogonal direction to the tool path than parallel to it [5]. Moreover, it is obvious that the smaller the distance of indentation and stepover distance as well as the lower the feed rate are chosen, the more overlap and therefore higher energy is induced [6]. The distance of indentation is influenced by the choice of feed rate and the applied frequency of the actuator's oscillation. In general, for ductile materials the surface roughness will be decreased by increasing the tool tip diameter. Apart from that, increasing stepover distance, hardness of the tool tip and feed rate will lead to greater surface roughness. For most applications, the main cause for an increase in work hardening of the surface layer is a decreasing tool tip diameter [6]. In addition, the microstructure may be influenced by MHP, which is further investigated in [7].

\section{Machining setup for the mechanical functionalisation of cutting inserts}

To ensure the machining of cutting inserts by the use of machine hammer peening, a clamping system was designed and manufactured (see Fig. 2a). It should provide appropriate fixation and orientation in the machining centre of both the clamping and the cutting tools to be processed. This clamping system consists of a substructure out of conventional hardened steel with a plate of carbide metal mounted on its top. The top plate has four recesses, which represent the precise negative form of the cutting inserts. Moreover, the substructure may be used for additional top plates according to other types of cutting inserts.

In Fig. 2b, the setup for MHP-treating of cutting inserts in the machining centre is shown. Herein, the MHP-actuator as well as the designed clamping system is depicted. The research work was carried out on a 5-axis machining centre (Hermle C20 U). 


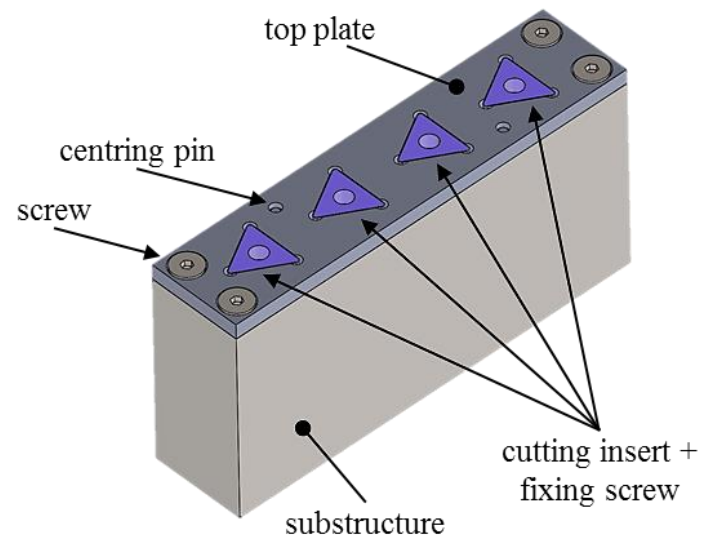

(a)

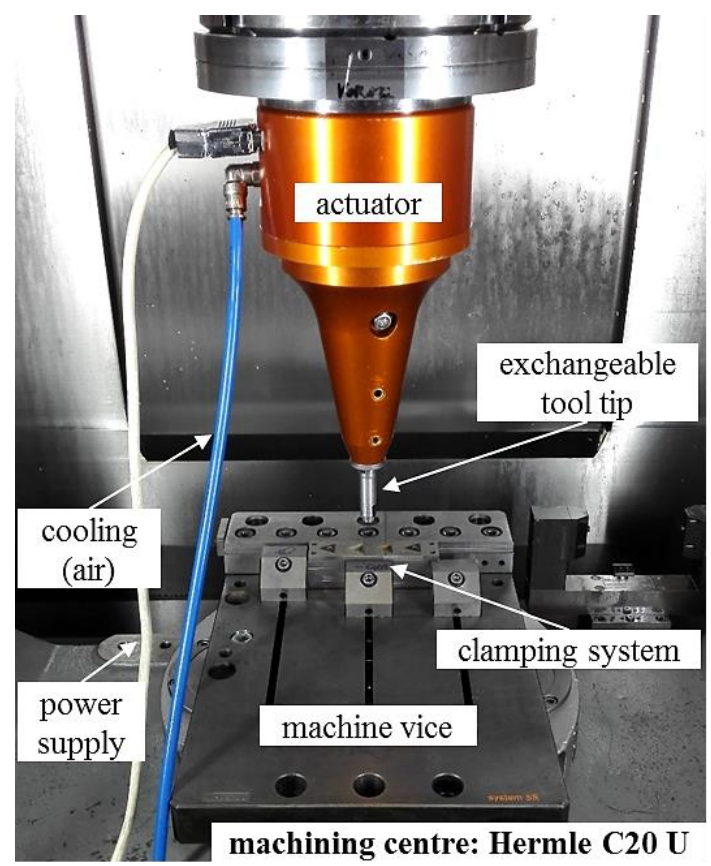

(b)

Fig. 2. (a) CAD-model of designed clamping system for the mechanical functionalisation of cutting inserts; (b) experimental setup in the machining centre.

\section{Configuration of the machining process}

The main advantage of the MHP-process in combination with NC-machines is the precise machining of workpieces. Therefore, different NC-strategies for the exact movement of the oscillating hammer peening device across the cutting inserts were investigated. The final form of the tool paths on the cutting insert's rake face is shown in Fig. 3. This strategy was chosen due to optimized results compared to earlier attempts that led to damaged cutting inserts, as used tool path arrangements were placed too close to the cutting edge or even across the cutting edges. The finally chosen strategy could be placed at the required distance to the cutting edge without damaging it.

Furthermore, the process parameters have been investigated and tested. As already discussed in section 2, the stepover distance and the distance of indentation were set very low to create a high percentage of overlapping tool paths on the processed areas. This is also the reason for a relatively high stroke value that delivers a significant amount of kinetic energy to the ram, which is transformed into mechanical deformation of the cutting insert. The subsequently applied process parameters are listed in Table 1.

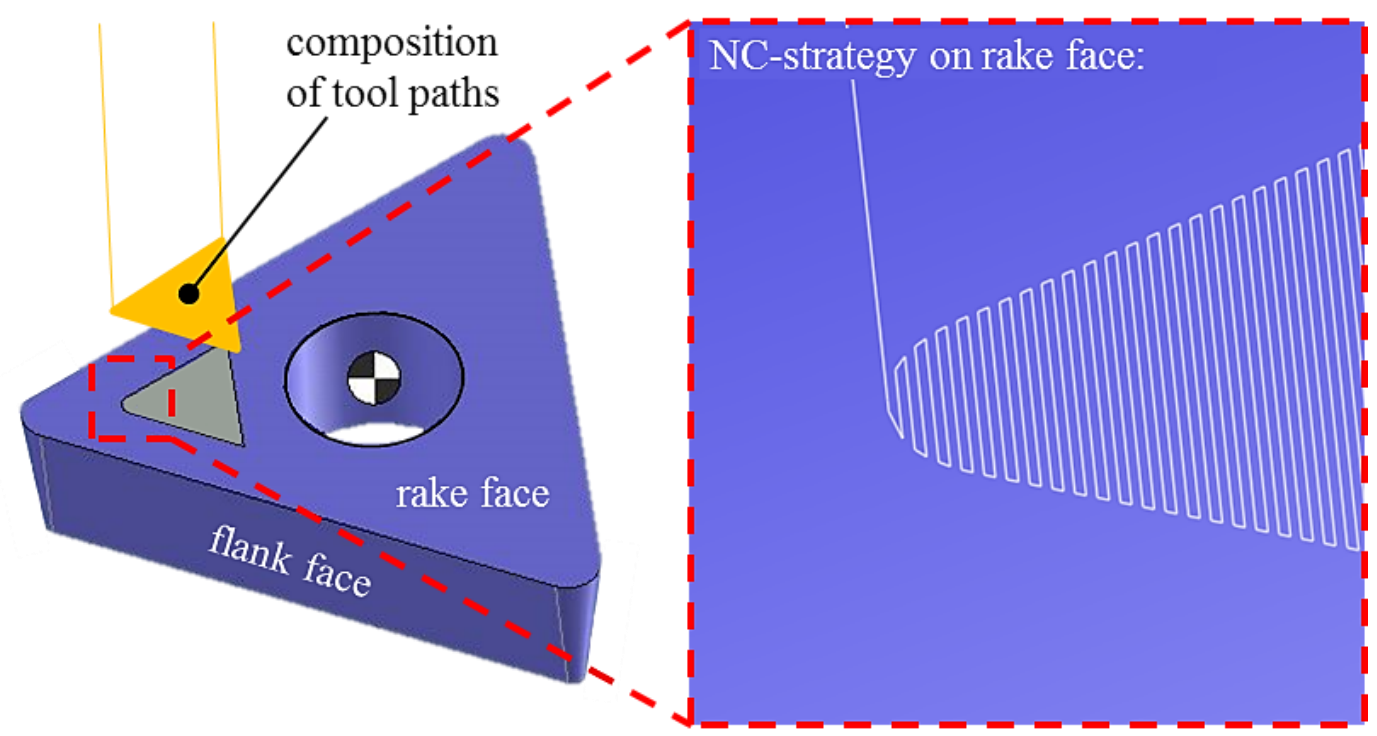

Fig. 3. CAD-model of cutting insert with final NC-strategy. 


\begin{tabular}{|l|r|}
\hline Intensity $(I)$ & $100 \%$ \\
\hline Frequency $(f)$ & $200 \mathrm{~Hz}$ \\
\hline Feed rate $(v)$ & $1.200 \mathrm{~mm} / \mathrm{min}$ \\
\hline Distance of indentation $(a)$ & $0,1 \mathrm{~mm}$ \\
\hline Stepover distance $(s)$ & $0,02 \mathrm{~mm}$ \\
\hline Tool tip diameter $(d)$ & $6 \mathrm{~mm}$ \\
\hline Stroke $(h)$ & $0,5 \mathrm{~mm}$ \\
\hline
\end{tabular}

Table 1. Process parameters.

Various materials of the tool tip were investigated, with the best results reached using the carbide metal tool tip. Other tip materials that have particularly higher hardness, e.g. ceramic materials, showed poor wear behaviour like flat spots after just a single machining sequence, fine cracks on the spherical surface, etc. Moreover, the amounts of induced residual compressive stresses on the cutting insert resulted in considerably smaller values (see also section 5.2).

\section{Effects on the processed surface layers}

To verify the orthogonal distance of the MHP-treated area to the cutting edge and to gain knowledge of the reached depths due to mechanical deformation on the cutting insert, optical measurements were carried out using a digital microscope as well as a 3D surface measuring device. The detection of residual stresses in near-surface regions of the MHP-treated cutting inserts were carried out by means of X-ray diffraction measurements.

\subsection{Optical measurements}

In the upper section of Fig. 4, the corner of a cutting insert right after MHP-treatment is shown, where no postprocess cleaning had taken place, and therefore marks of abrasion are still visible. For this specific insert, that was processed with the above presented NC-strategy (Fig. 3) and process parameters (Table 1), the orthogonal distance of the MHP-treated area to the cutting edge was just $0,7 \mathrm{~mm}$. The image was taken using a Keyence $V W-9000$ digital microscope with a $100 \mathrm{x}$ magnification. Further measurements, especially to get quantitative knowledge of the mechanical deformation of the MHP-treated areas, were carried out using an Alicona InfiniteFocus G4 3D surface measuring device, with a vertical resolution of $250 \mathrm{~nm}$ and a lateral resolution of $5 \mu \mathrm{m}$ regarding a 10x magnification. Concerning this, the lower section of Fig. 4 shows the false-colour plot and the belonging depth profile of the marked area on the cutting insert.

The orthogonal distance between MHP-treated area (composed of the strung together tool paths) and cutting edge of $0,7 \mathrm{~mm}$ was defined as a default value. Former experiments using this distance and the favoured process parameters (Table 1) showed positive results, thus the stable processing of the cutting inserts have been ensured.

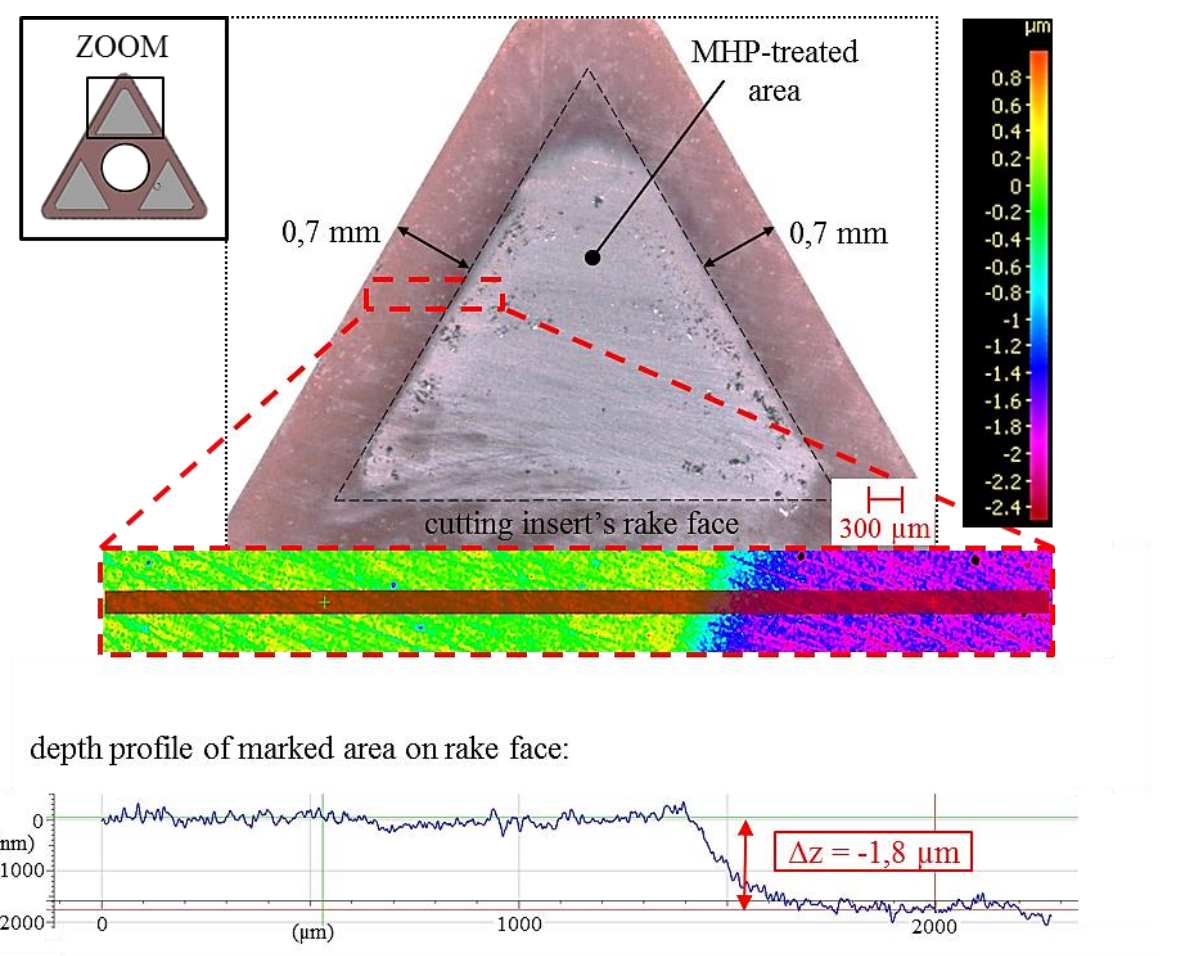

Fig. 4. Microscopic image of the MHP-treated cutting insert and depth profile of marked area on the rake face. 
As visible in Fig. 4, an overall depth difference (from the untreated to the treated surface) of 1,8 $\mu \mathrm{m}$ was measured for the marked area of the cutting insert's rake face. Due to this significant mechanical deformation respectively material compaction, residual compressive stresses should be induced as well as the hardness in the subsurface layers may be increased (see section 5.2).

\section{2. $X$-ray diffraction measurements}

X-ray diffraction (XRD) belongs to the group of non-destructive testing methods for residual stresses on material surfaces. It bases, according to its indication, on the diffraction of ordered structures like in crystalline metal. As a result of mechanical stress, the spacing between atomic planes in the structure change, which leads to different diffraction patterns before and after applying the load. The resulting values deliver information on the strains in the material, and therefore the material's residual stresses can be calculated. The underlying principle for this kind of diffraction is the socalled Bragg equation (1). For further relevant information regarding Bragg's law and X-ray diffraction, see referred literature, e.g. [8],[9].

$$
\begin{aligned}
& n * \lambda=2 * d * \sin \theta \\
& n \ldots \text { integer (typically } 1) \\
& \lambda \ldots \text { X-ray wavelength } \\
& d \ldots \text { lattice spacing } \\
& \theta \ldots \text { diffraction angle (so-called Bragg-angle) }
\end{aligned}
$$

The X-ray diffraction measurements were carried out using a Bruker D8 Discover device. As the coating has a thickness of approximately $10 \mu \mathrm{m}$ and the depth of the X-ray diffraction is under $10 \mu \mathrm{m}$, the induced residual stresses in the coating could be measured. The measurement point was placed in the centre of the machined triangular area, but the XRD-measurements were performed in orthogonal direction to the cutting edge (see schematical drawing in Fig. 5b). This is the crucial direction for the cutting tool, because the material cutting occurs also in orthogonal direction to the cutting edge. In Fig. 5a, the resulting residual stress values in the subsurface layers of the cutting insert's rake face are shown. This specific cutting insert was machined as follows: Corner 1 functioned as a measuring reference (no MHPtreatment, cutting insert respectively coated material in as-delivered condition). Corner 2 was MHP-treated with the presented process parameters (Table 1) and NC-strategy (Fig. 3; with the default distance of 0,7 mm to the cutting edge). Corner 3 was machined in the same way as corner 2, but was MHP-treated twice.

After the machining, corner 2 showed an overall depth difference from the untreated to the treated surface on the rake face of about $1,4 \mu \mathrm{m}$, as it was measured over the entire width of the cutting edge (from the main cutting edge to the minor cutting edge). This is the reason for the discrepancy in depth to the example in section 1, which was measured just in a small area on the outside of the MHP-treated area, where the turnaround of the tool paths happened and therefore more indentations took place. The overall depth difference to corner 3 was measured approximately $2,2 \mu \mathrm{m}$, in the same way as corner 2 .

It can be seen that the reference point shows minimal residual tensile stresses. Corner 2 shows significant induced residual compressive stresses, which was already expected due to the mechanical deformation of the processed area. Corner 3 shows higher induced residual stresses than corner 2, but as also mentioned in [6] and considering the given confidence intervals, double treatment does not change the amount of residual stresses in a neither significant nor proportional manner.

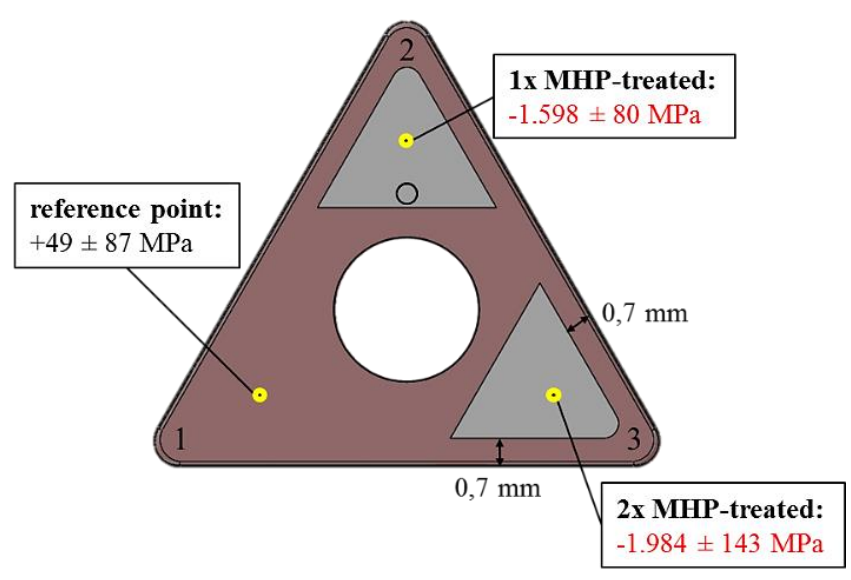

(a)

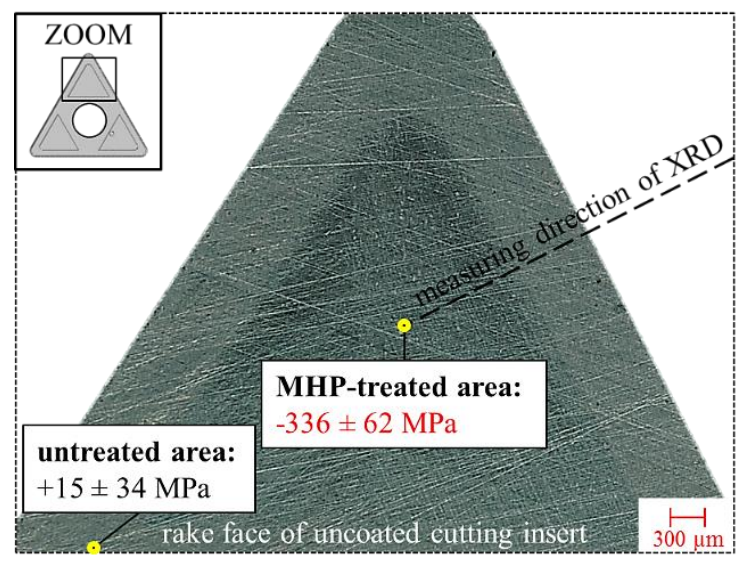

(b)

Fig. 5. (a) Schematic overview of MHP-treated areas on the cutting insert's rake face and measured residual stresses; (b) image of the MHP-treated uncoated cutting insert and the measured residual stresses. 
The MHP-treatment was also performed on uncoated inserts (with the same process parameters as in Table 1 and NC-strategy as in Fig. 3) to prove the inducement of residual compressive stresses not only into the coating, but also in the subjacent substrate. The X-ray diffraction measurements therefore also showed an inducement of compressive residual stresses in the substrate, although the outcomes were at a lower level than for the coating (see Fig. 5b). The processed area on the uncoated cutting insert can be seen as a shaded, triangular field (image taken using the Keyence VW-9000 digital microscope).

As already mentioned, residual stress measurements of the cutting inserts that were MHP-treated with ceramic tool tip materials (aluminium oxide $\mathrm{Al}_{2} \mathrm{O}_{3}$ and silicon nitride $\mathrm{Si}_{3} \mathrm{~N}_{4}$ ) instead of carbide metal have been performed. The generated findings pointed out that these tool tip materials had too high wear susceptibility. Therefore, the resulting residual compressive stresses of the machined areas on the cutting insert's rake face were significantly lower than for the carbide metal tip - less than half the stress value of the ones processed with the carbide metal tip was reached (subject to the use of the identical cutting inserts, the same process parameters as in Table 1 and the same NC-strategy as depicted in Fig. 3).

\section{Conclusion and outlook}

The present work's focus was on the mechanical functionalisation of cutting inserts that are usually applied for the simultaneous machining of a material combination. Due to this functionalisation, caused by the use of machine hammer peening, the processed surface area on the cutting insert's rake face should show induced residual compressive stresses.

In conclusion, the positive effects of machine hammer peening for the application on cutting inserts have been successfully demonstrated. Due to the previous investigations and setting of appropriate processing parameters as well as suitable arrangement of tool paths, a significant material compaction has been reached on the cutting insert's rake face by means of machine hammer peening. Hence, a major amount of residual compressive stresses has been induced into the coating and also the sintered substrate beneath.

The aim of further investigations should analyse the effects on the hardening of subjacent layers of the MHP-treated areas. In addition, greater insight into the impacts of MHP-treatment on the coating-substrate bond, as it was a cemented tungsten carbide substrate with Ti-Al-N coating for this present research, have to be gained. The consequences on the performance of the cutting tool, especially the reachable tool life, must be further investigated in experimental cutting tests. Subject to the success of these mentioned and further future developments, this kind of mechanical functionalisation of cutting tools may be established in the field of production engineering to consequently lower production costs and improve sustainability.

\section{References}

[1] C. Lechner, F. Bleicher, C. Habersohn, C. Bauer \& S. Gössinger (2012). "The use of machine hammer peening technology for smoothening and structuring of surfaces," Proc. 23rd Int. DAAAM Symp., vol. 23, pp. 331-336.

[2] D. H. Trauth (2016). Tribology of Machine Hammer Peened Tool Surface for Deep Drawing. Aachen: Apprimus Verlag.

[3] D. Boehnke (2007). Qualitätsorientierte Zerspanung von Parallelverbunden im kontinuierlichen Schnitt. Hannover: PZH, Produktionstechn. Zentrum.

[4] C. Lechner (2014). "Oberflächenmodifikation unter Einsatz der Technologie des Schlagverdichtens (Machine Hammer Peenings)," Technische Universität Wien.

[5] F. Bleicher, C. Lechner, C. Habersohn, E. Kozeschnik, B. Adjassoho \& H. Kaminski (2012). "Mechanism of surface modification using machine hammer peening technology," CIRP Ann. - Manuf. Technol.

[6] V. Schulze, F. Bleicher, P. Groche, Y. B. Guo \& Y. S. Pyun (2016). "Surface modification by machine hammer peening and burnishing," CIRP Ann. - Manuf. Technol., vol. 65, no. 2, pp. 809-832.

[7] B. Adjassoho et al. (2013). "Controlled surface treatment with machine hammer peening," Met. 2013, Brno, vol. 4, pp. 13-18.

[8] N. S. Rossini, M. Dassisti, K. Y. Benyounis \& A. G. Olabi (2012). "Methods of measuring residual stresses in components," Mater. Des., vol. 35, pp. 572-588.

[9] P. S. Prevéy (1996). "Current applications of X-ray diffraction residual stress measurement,” Dev. Mater. Charact. Technol., no. 513, pp. 103-110. 